\title{
Robustness analysis of control strategy in double-fed wind generators
}

\author{
L. Y. Chen" ${ }^{*}$ Z. R Jia, Z. Y. Li \\ Department of Electrical Engineering, Zhejiang University, Hangzhou 310027, China
}

\begin{abstract}
As for power system planning, it is difficult to acquire the detailed model of wind generators to be installed because of the commercial secrets. The mathematical models and typical control strategies of double-fed wind generator (DFIG) were discussed in this paper and the simulation model was established under the environment of power system simulation software DIgSILENT. Then two typical vector control methods applied in DFIG-stator flux oriented control and stator voltage oriented control were compared from two aspects which were eigenvalue and dynamic response, Furthermore, the influence of ignoring some fast dynamic links was also discussed. It can be concluded that when suffered a large disturbance, the proposed two vector control methods are quite different, and it is necessary to consider more detailed model in system stability analysis. On the contrary, when small disturbance is supposed, the results of two control methods are almost identical, which illustrates strong robustness and small deviation by applying general model.
\end{abstract}

Keywords: Double-fed wind generator, DIgSILENT, stator flux oriented control, stator voltage oriented control, eigenvalue analysis

\section{Introduction}

At present, there is a growing emphasis on wind energy, which is one of the new energy having the potential of large-scale development and utilization. Due to a series of advantages, variable speed constant frequency (VSCF) DFIG is gradually becoming the mainstream product in the grid-connected wind generator market [1]. In the power grid having high penetration of wind power, the ability of effective control of accessed wind power, is directly related to the security and stability of the entire power system operation. Consequently, the research about control strategy in DFIG is bringing more and more attention [2], [3].

Currently, the control strategy in DFIG mainly includes direct torque control strategy (DTC), direct power control strategy (DPC) and vector control strategies [4]-[9]. Compared with other control strategies, the vector control strategy has characteristics of simple principle, easy to implement, strong robustness and high control precision, thus it has been widely used. From the existing literature, most of rotor-side converter controls in DFIG adopt the stator flux oriented or stator voltage oriented vector control [10][12]. The reason is that the stator port active and reactive power expressions form is concise after orientation, which is beneficial to the formation and implementation of the control system.

Considering commercial interests, the detailed models of wind generator are mastered by manufacturers. It brings great difficulties to analysis the large-scale wind power integrated power system. Therefore, establishing the general DFIG simulation model with sufficient accuracy becomes of great significance in meeting the needs of research work. Now most of the literatures only focus on improving the performance of the controller in wind generator. Little comparative analysis is made on robustness between different control strategies, while the robustness difference under a variety of operating conditions and control strategies has important reference value for choosing the wind generator control

\footnotetext{
* Manuscript received July 10, 2013; revised August 16, 2013.

Corresponding author. Tel.: 13656698129;E-mail address: clyyuanzi@126.com.
} 
strategy.

To solve above problems, this paper will establish general simulation model of DFIG under the environment of power system analysis software DIgSILENT. Furthermore, we discuss the currently widely used stator flux oriented control and stator voltage oriented control, compared and analyzed their dynamic characteristics from the aspects of the eigenvalue and dynamic response, thus illustrate robustness of the two control strategies under the conditions of different simulation requirements.

\section{Mathematical Model and Basic Structure of DFIG}

\subsection{Basic topology structure of DFIG}

The structure of DFIG is similar to wound-rotor asynchronous motor. As shown in Fig. 1, the stator winding is directly connected to the grid through a boosting transformer, while the rotor winding is through a back-to-back PWM converter called rotor-side converter and grid-side converter, respectively. The main function of rotor-side and grid-side converter is to achieve the decoupling control of active and reactive power and maintain the DC bus voltage stability. As the excitation control of DFIG, the rotorside converter control is the key component of the whole system, also the main study subject in this paper.

\subsection{Mathematical model of DFIG}

Stator winding adopts motor convention, namely the positive direction of stator and rotor currents is inflow, the same direction of the current corresponding to flux. The per-unit value equation of DFIG stator and rotor voltage in the $\mathrm{d}-\mathrm{q}$ coordinate system is:

$$
\left\{\begin{array}{l}
u_{s d}=p \psi_{s d}-\omega_{s} \psi_{s q}+R_{s} i_{s d} \\
u_{s q}=p \psi_{s q}+\omega_{s} \psi_{s d}+R_{s} i_{s q} \\
u_{r d}=p \psi_{r d}-s \omega_{s} \psi_{r q}+R_{r} i_{r d} \\
u_{r q}=p \psi_{r q}+s \omega_{s} \psi_{r d}+R_{r} i_{r q}
\end{array}\right.
$$

The equation of magnetic flux linkage is:

$$
\left\{\begin{array}{l}
\psi_{s d}=L_{s} i_{s d}+L_{m} i_{r d} \\
\psi_{s q}=L_{s} i_{s q}+L_{m} i_{r q} \\
\psi_{r d}=L_{m} i_{s d}+L_{r} i_{r d} \\
\psi_{r q}=L_{m} i_{s q}+L_{r} i_{r q}
\end{array}\right.
$$

where $u_{s d}, u_{s q}, u_{r d}, u_{r q}$ are d, q-axis component of stator and rotor voltage, respectively; $\psi_{s d}, \psi_{s q}, \psi_{r d}, \psi_{r q}$ are $\mathrm{d}$, q-axis component of stator and rotor magnetic flux linkage, respectively; $\omega_{s}$ is synchronous angular speed; $s$ is slip; $i_{s d}, i_{s q}, i_{r d}, i_{r q}$ are d, q-axis component of stator and rotor current, respectively; $R_{s}, R_{r}$ are winding resistance of stator and rotor winding; $L_{s}, L_{r}, L_{m}$ are self-inductance of stator and rotor and excitation reactance.

\section{DFIG Control Model}

\subsection{Control strategy of prime mover}

Prime mover is the part of wind power generation to obtain mechanical energy, which directly affects the efficiency of wind power generation system. The mechanical energy for the prime mover obtained from wind energy is [2]:

$$
P_{m}=1 / 2 \rho A C_{P} v^{3}
$$

where $\rho$ is air density; $A$ is the frontal area of the wind turbine blades; $C_{p}$ is wind energy utilization factor, which is the function of the pitch angle $\beta$ and the tip speed ratio $\lambda(\lambda=\omega R / v, \omega$ is wind turbine speed, $R$ is the radius of the wind turbine blades, $v$ is the external wind speed). When the external wind speed is 
below the rated wind speed, the wind generation operates at maximum power tracking (MPPT) mode by making the wind generation speed changing with the external wind speed. When the wind speed exceeds the rated speed, the pitch angle controller plays a role in achieving the purpose of limiting the power output of the wind generation by controlling the pitch angle $\beta$. The overall topology of the prime mover control is shown in Fig. 2 [13].

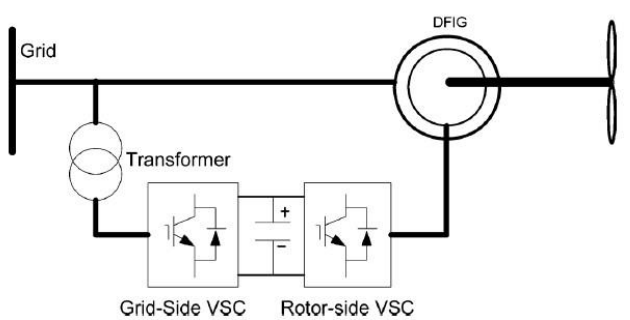

Fig. 1. Basic structure of DFIG.

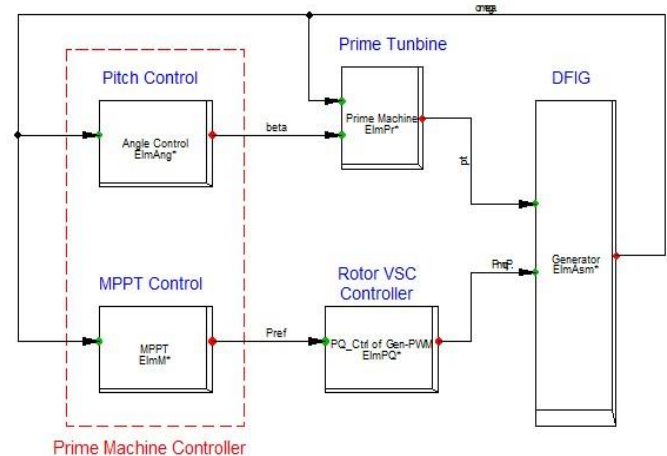

Fig. 2. Topology of prime mover control.

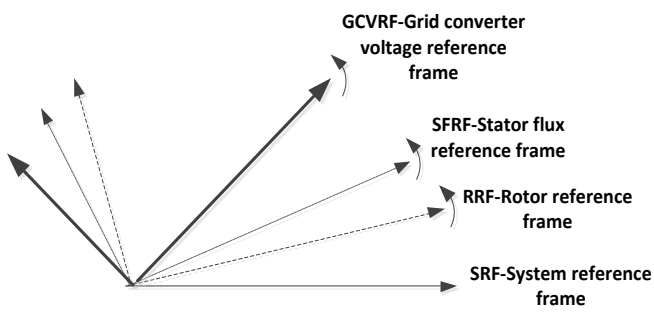

Fig. 3. Coordinate system of DFIG.

\subsection{Control strategy of rotor side PWM converter}

\subsubsection{Stator-flux oriented control}

The coordinate system cluster used in DFIG is shown in Fig. 3, where SRF is synchronous speed reference coordinate system. RRF is rotor reference coordinate system. In a generator or motor, d-axis is tend to choose as the direction of rotor's excitation magnetic flux, while q-axis leads the d-axis by 90 degrees. SFRF is stator magnetic flux reference coordinate system, which applied in the stator flux oriented vector control method; GCVRF is grid-converter voltage reference coordinate system.

The stator flux oriented method adopts SFRF reference coordinate system shown in Fig. 4. It considers the positive direction of d-axis is in accordance with stator flux direction, and q-axis ahead d-axis by $90^{\circ}$. Here the output active and reactive power in DFIG is:

$$
\left\{\begin{array}{l}
P_{E}=-u_{s q}\left(\frac{\psi_{s q}-L_{m} i_{r q}}{L_{s}}\right) \approx \frac{L_{m}}{L_{s}} u_{s q} i_{r q} \\
Q_{E}=u_{s q}\left(\frac{-\psi_{s d}+L_{m} i_{r d}}{L_{s}}\right) \approx-\frac{\psi_{s} u_{s q}}{L_{s}}+\frac{L_{m}}{L_{s}} u_{s q} i_{r d}
\end{array}\right.
$$

The above equation shows that just controlling the q-axis and d-axis current of rotor excitation current respectively, the decoupling control of active and reactive power in DFIG can be realized. Since stator flux is the integral value of stator voltage, the change in flux is gentle and no mutation happens, making the whole control easier to implement. Detailed control diagram shown in Fig. 4. However, the stator flux oriented method also has shortcomings, among which a crucial factor is the difficult measurement of stator flux vector. The literature [14], [15] detailed study this issue and put forward a series of improvement approaches. 


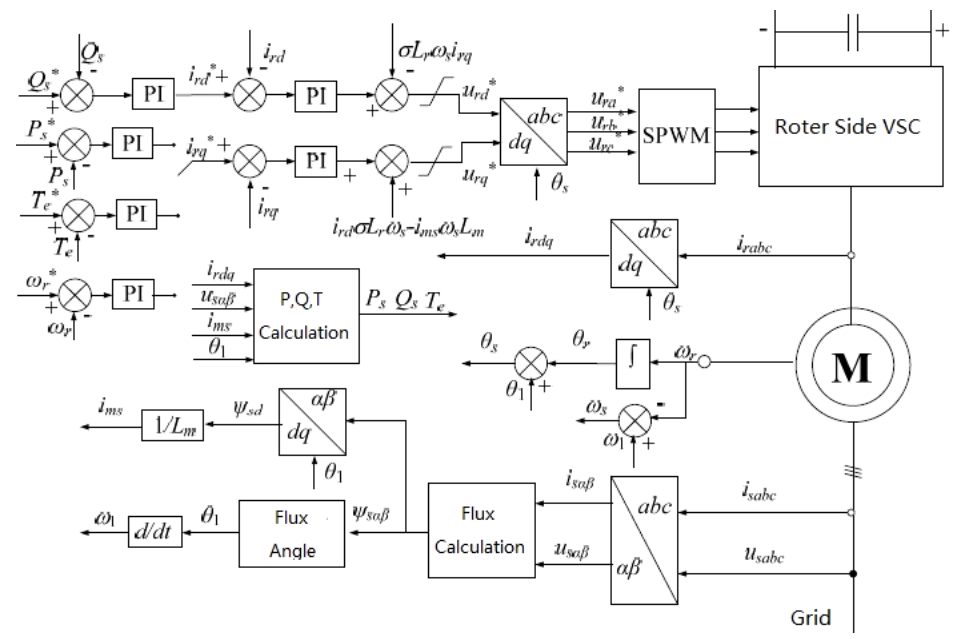

Fig. 4. Stator flux oriented control system.

\subsubsection{Stator-voltage oriented control}

The control strategy of stator voltage oriented vector can achieve decoupling control of active and reactive power in DFIG. The method assumes that the positive direction of d-axis coincides with the direction of stator voltage vector, and q-axis leads d-axis by $90^{\circ}$. Here the output active power and reactive power of DFIG is:

$$
\left\{\begin{array}{l}
P_{E}=-u_{s d}\left(\frac{\psi_{s d}-L_{m} i_{r d}}{L_{s}}\right) \approx \frac{L_{m}}{L_{s}} u_{s d} i_{r d} \\
Q_{E}=u_{s d}\left(\frac{\psi_{s q}-L_{m} i_{r q}}{L_{s}}\right) \approx \frac{\psi_{s q}}{L_{s}} u_{s d}-\frac{L_{m}}{L_{s}} u_{s d} i_{r q}
\end{array}\right.
$$

Different with the stator flux oriented method, the stator voltage oriented method controls active power by changing the rotor $\mathrm{d}$-axis excitation current, and control reactive power by changing the q-axis current. Detailed control diagram is shown in Fig. 5.

The stator voltage oriented control strategy has strong robustness and high control accuracy, also easier to detect voltage vector angle compared with stator flux orientation. However, the control model involves the calculation of the rotor flux. In fact, the parameters' change caused by parameter measurement accuracy and temperature rise, especially the parameter changes of motor rotor circuit, will reduce accuracy of control model.

\section{Comparison Analysis}

As the proportion of the wind turbine increased in the electrical power system, the choice of the wind turbine control methods played a significant role in the influence on system stability. The last chapter shows that, the difference between the flux oriented and the voltage oriented control is on the coordinate axis for changing $90^{\circ}$ while the others part are totally the same once the circuits resistance is omitted. For the purpose of study the character of the dynamic procedure, this chapter will make a comparison and analysis on the robustness for the two control methods by studying the eigenvalues and dynamic features.

Through power system simulation software DIgSILENT, a model for DFIG and its control system is established. A typical 1.5 MW DFIG was utilized in the simulation and its parameters were: the rated mechanical power $1.29 \mathrm{MW}$, generator terminal voltage $690 \mathrm{~V}$, the rotor voltage $1.1 \mathrm{kV}$, frequency $50 \mathrm{~Hz}$ and pole-pairs $n_{p}=2$.

\subsection{Eigenvalue analysis}

Since we do consider about the eigenvalues closed to imaginary axis which have bigger influence on 
the system stability, the Arnoldi/Lanczos method for solving partial eigenvalues is utilized here. In order to avoid the interference from other factors, the generator was connected to the infinite grid through routes and both of the control approaches were based on the same controlling parameters. Table 1 shows 4 sorts of wind turbine outputs scheme. The two kinds of control methods were used respectively here and the corresponding eigenvalues closed to the imaginary axis of the system are demonstrated as follows:

In the case when the DFIG was under a small disturbance, Table 2 to Table 5 indicates that:

1) The eigenvalues of the system vary as the wind turbine outputs power rises, which means the system stability increases when the wind turbine outputs rises. However, the effect is quite small.

2) The wind turbine outputs reactive power has a larger influence on the system stability compared with the active one.

3) The eigenvalues of the system based on those two control methods differ from each other but the difference is small on the case of the identical wind turbine outputs. The calculation results showed that the biggest damping ratio deviation was no larger than $1 \%$ for the same oscillation mode.

The eigenvalues analysis results show that the system stability was hardly affected by the wind turbine outputs when the system itself was under a small disturbance. Moreover, the influences on the system stability by applying two control approaches were nearly the same. It's unnecessary to distinguish those two control methods in this occasion so that we can neglect the system stability when we choose the control strategy. It shows strong robustness and small deviation by applying general models.

Table 1. Wind turbine outputs

\begin{tabular}{ccc}
\hline \hline \multirow{2}{*}{ No. } & \multicolumn{2}{c}{ Wind turbine outputs } \\
\cline { 2 - 3 } & Active power (p.u.) & Reactive power (p.u.) \\
\hline 1 & 0.2 & 0.2 \\
2 & 0.2 & 0.8 \\
3 & 0.8 & 0.2 \\
4 & 0.6 & 0.6 \\
\hline \hline
\end{tabular}

Table 2. Part of the eigenvalues in scenario 1

\begin{tabular}{ccc}
\hline \multirow{2}{*}{ No. } & \multicolumn{2}{c}{ Eigenvalues } \\
\cline { 2 - 3 } & Flux oriented & Voltage oriented \\
\hline 1 & -0.500 & -0.500 \\
2 & -1.668 & -1.668 \\
3 & -2.260 & -2.260 \\
4 & -3.926 & -3.926 \\
5 & -4.882 & -4.882 \\
6 & $-2.647 \pm \mathrm{j} 3.258$ & $-2.648 \pm \mathrm{j} 3.257$ \\
7 & $-2.100 \pm \mathrm{j} 6.918$ & $-2.098 \pm \mathrm{j} 6.914$ \\
8 & -10.000 & -10.000 \\
9 & -16.667 & -16.667 \\
10 & $-38.500 \pm \mathrm{j} 80.217$ & $-36.950 \pm \mathrm{j} 77.728$ \\
11 & $-49.604 \pm \mathrm{j} 110.517$ & $-52.871 \pm \mathrm{j} 114.466$ \\
12 & -341.671 & -343.724 \\
\hline \hline
\end{tabular}

Table 4. Part of the eigenvalues in scenario 3

\begin{tabular}{ccc}
\hline \multirow{2}{*}{ No. } & \multicolumn{2}{c}{ Eigenvalues } \\
\cline { 2 - 3 } & Flux oriented & Voltage oriented \\
\hline 1 & -0.500 & -0.500 \\
2 & -1.670 & -1.670 \\
3 & -2.253 & -2.253 \\
4 & -3.922 & -3.922 \\
5 & -4.899 & -4.895 \\
6 & $-2.465 \pm \mathrm{j} 3.565$ & $-2.467 \pm \mathrm{j} 3.564$ \\
7 & $-2.162 \pm \mathrm{j} 6.635$ & $-2.160 \pm \mathrm{j} 6.631$ \\
8 & $-5.009 \pm \mathrm{j} 29.728$ & $-4.781 \pm \mathrm{j} 29.508$ \\
9 & -10.000 & -10.000 \\
10 & -16.667 & -16.667 \\
11 & $-39.275 \pm \mathrm{j} 80.443$ & $-38.207 \pm \mathrm{j} 77.068$ \\
12 & $-49.344 \pm \mathrm{j} 107.686$ & $-51.622 \pm \mathrm{j} 112.960$ \\
13 & -354.680 & -357.166 \\
\hline \hline
\end{tabular}

Table 3. Part of the eigenvalues in scenario 2

\begin{tabular}{ccc}
\hline \multirow{2}{*}{ No. } & \multicolumn{2}{c}{ Eigenvalues } \\
\cline { 2 - 3 } & Flux oriented & Voltage oriented \\
\hline 1 & -0.500 & -0.500 \\
2 & -1.668 & -1.668 \\
3 & -2.340 & -2.340 \\
4 & -3.702 & -3.703 \\
5 & -5.104 & -5.104 \\
6 & $-1.396 \pm \mathrm{j} 4.572$ & $-1.395 \pm \mathrm{j} 4.574$ \\
7 & $-4.199 \pm \mathrm{j} 5.615$ & $-4.196 \pm \mathrm{j} 5.602$ \\
8 & $-5.264 \pm \mathrm{j} 30.497$ & $-4.910 \pm \mathrm{j} 30.099$ \\
9 & -10.000 & -10.000 \\
10 & -16.667 & -16.667 \\
11 & $-38.944 \pm \mathrm{j} 82.435$ & $-37.417 \pm \mathrm{j} 79.632$ \\
12 & $-50.637 \pm \mathrm{j} 111.166$ & $-55.310 \pm \mathrm{j} 115.817$ \\
13 & -363.641 & -367.030 \\
\hline \hline
\end{tabular}

Table 5. Part of the eigenvalues in scenario 4

\begin{tabular}{ccc}
\hline \hline \multirow{2}{*}{ No. } & \multicolumn{2}{c}{ Eigenvalues } \\
\cline { 2 - 3 } & Flux oriented & Voltage oriented \\
\hline 1 & -0.500 & -0.500 \\
2 & -1.669 & -1.669 \\
3 & -2.307 & -2.307 \\
4 & -3.776 & -3.776 \\
5 & -5.044 & -5.042 \\
6 & $-1.664 \pm 4.641$ & $-1.664 \pm 4.645$ \\
7 & $-3.577 \pm 5.574$ & $-3.575 \pm 5.561$ \\
8 & $-5.176 \pm \mathrm{j} 30.225$ & $-4.845 \pm \mathrm{j} 29.885$ \\
9 & -10.000 & -10.000 \\
10 & -16.667 & -16.667 \\
11 & $-39.382 \pm \mathrm{j} 81.933$ & $-38.117 \pm \mathrm{j} 78.649$ \\
12 & $-50.009 \pm \mathrm{j} 109.111$ & $-53.650 \pm \mathrm{j} 114.396$ \\
13 & -365.467 & -368.679 \\
\hline \hline
\end{tabular}




\section{International Journal of Smart Grid and Clean Energy}

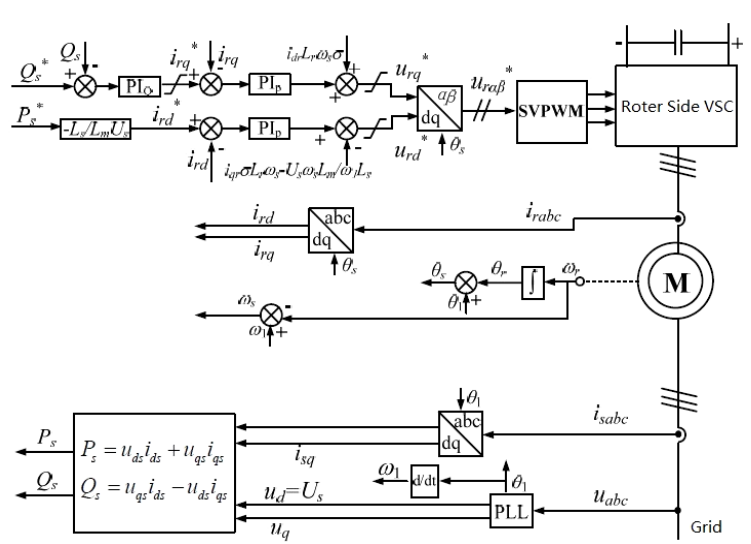

Fig. 5. Stator voltage oriented control system.

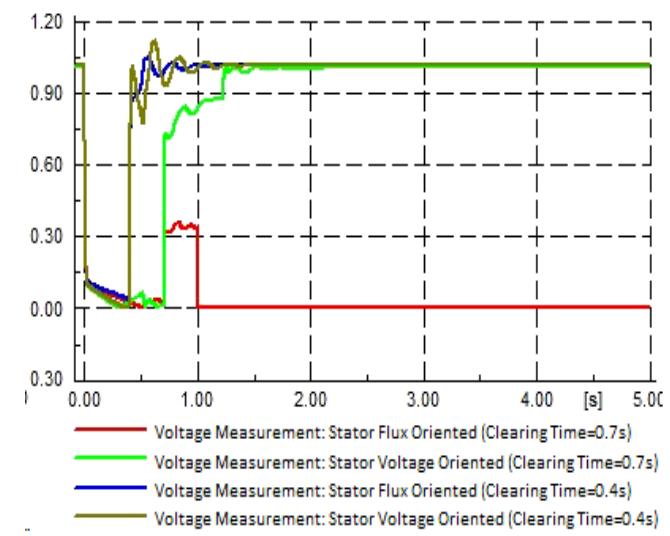

Fig. 6. Dynamic response of system voltage under shortcut fault.

\subsection{Time-domain simulation analysis}

The last section made a comparison on the two control strategies under a small disturbance. This section will take the system dynamic response for the two different control methods into consideration under a big disturbance in the time-domain simulation.

To imitate a big disturbance, we assumed there was a three-phase short circuit fault in the interconnection point of the DFIG. We judged the voltage instability according to whether the voltage could revert to 0.85 p.u. within $3 \mathrm{~s}$ after the contingency. For example, the DFIG outputs active power was 0.7 p.u. and reactive power was 0.24 p.u.. A three-phase short circuit fault took place on the interconnection point. Fig. 8 shows the dynamic response of the interconnection point voltage when the fault was cleared at $0.4 \mathrm{~s}$ and $0.7 \mathrm{~s}$. Fig. 6 shows that the system interconnection voltage could revert to the original value when the fault was cleared at $0.4 \mathrm{~s}$ by applying the two control methods. The system voltage was not instable on this occasion. However, the system voltage could revert to the original value faster by applying the stator flux oriented control approach since the flux would not suddenly change when the fault occurred. When the fault was fixed at $0.7 \mathrm{~s}$, Fig. 6 shows that the system voltage has been already instable after the fault by applying the stator flux oriented method. But the system voltage could revert to the original value by the stator voltage oriented one.

To find out the influence on the system stability through the two control strategies and to make sure a stable system voltage, this article set the maximum fault clear time as the evaluation index. On the other hand, we also considered different outputs in order to thoroughly compare the two control strategies. The results are demonstrated as Table 6.

Table 6 shows the information when the wind turbine was under a big disturbance as:

1) The maximum fault clear time had a trend of being smaller as the wind turbine outputs increased by applying the two control strategies. It indicated that the system stability got worse with an increase of the outputs power.

2) On most condition, the fault clear time by applying the voltage oriented method was larger than that by the flux oriented method. It told that the voltage oriented method could bring the better system stability.

3) The fault clear time by both of the control methods were almost the same when the wind turbine was nearly fully loaded, which illustrated the two methods almost had a same influence on the system stability.

Apparently, it was different from the analysis result above that the two control strategies still differ from each other when the wind turbine was under a big disturbance, which can be seen in Fig. 8 and Tab. 6. Consequently, we should treat those two strategies in different ways during the modelling procedure. For instance, the difference of the dynamic response feature between the two methods should be 
considered when analysing the wind turbine low voltage passing through and the system stability.

Table 6. Maximum fault clear time by applying two control strategies

\begin{tabular}{||cccc||cccc||}
\hline \multicolumn{2}{|c|}{ Outputs power (p.u.) } & \multicolumn{2}{c|}{ Max. fault clear time (s) } & \multicolumn{2}{c||}{ Outputs power (p.u.) } & \multicolumn{2}{c||}{ Max. fault clear time (s) } \\
\hline P (MW) & Q (Mvar) & Flux oriented & Voltage oriented & P (MW) & Q (Mvar) & Flux oriented & Voltage oriented \\
\hline & 0 & 0.67 & 0.75 & & 0 & 0.61 & 0.61 \\
0.23 & 0.12 & 0.66 & $>1$ & 0.70 & 0.12 & 0.68 & 0.87 \\
& 0.24 & 0.94 & $>1$ & & 0.24 & 0.69 & 0.86 \\
& 0.39 & 0.98 & $>1$ & & 0.39 & 0.87 & 0.87 \\
\hline & 0 & 0.61 & 0.65 & & 0 & 0.57 & 0.51 \\
0.46 & 0.12 & 0.59 & $>1$ & 0.93 & 0.12 & 0.56 & 0.51 \\
& 0.24 & 0.58 & $>1$ & & 0.24 & 0.51 & 0.51 \\
\hline
\end{tabular}

\section{Conclusion}

This article introduced the mathematical models and the typical control strategies of DFIG. We made analysis on the eigenvalues and the dynamic response in the simulation model. The robustness was analyzed with a comparison between applying the flux oriented control method and the voltage oriented one. Through our research, the two control strategies nearly had the same influence on the system stability under a small disturbance. It was unnecessary to distinguish these two methods on this occasion and we could use the general models to obtain a good robustness. On the contrary, there was a big difference between the two control methods when the wind turbine was under a big disturbance. So the difference should be taken into consideration during the modeling procedure when we study the wind turbine low voltage passing through, system stability and some other questions. The two methods should be distinguished according to the practical problems in order to choose a suitable strategy.

\section{References}

[1] Hui LS, Haskew TA. Analysis of decoupled d-q vector control in DFIG back-to-back PWM converter. Presented at: IEEE Power Engineering Society General Meeting, 2007.

[2] Bao W, Yin ZD, Ren ZH. VSCF DGIFAC excitation control system. Electric Drive, 2010; 40:27-32.

[3] ACKERMANN. (2005) Wind Power in Power Systems.

[4] Xun J, Huang XB, Liu CJ, et al. Stator voltage oriented DFIG system variable parameter strategy design. Power System Automation, 2010; 34:90-94.

[5] Wu XJ, Chai JY, Wang XY. VSCF DFIG AC excitation summary. Power System Automation, 2004; 28:92-96.

[6] Li H, Yang YC, Liao Y, He B. VSCF DFIG excitation control strategy summary. Electric Technology Magazine, 2002:4-8.

[7] Li S. Induction Motor Direct Torque Control. Beijing: Mechanical Industry Press, 2001.

[8] Arnalte S, et al. Direct torque control of a doubly-fed induction generator for variable speed wind turbines. Electric Power Components and Systems, 2002:199-216.

[9] Datta R, Ranganathan VT. Direct power control of grid-connected wound rotor induction machine without rotor position sensors. IEEE Transactions on Power Electronics, 2001; 16:390-399.

[10] Bose BK, Patel NR. A programmable cascaded low-pass filter-based flux synthesis for a stator flux-oriented vector-controlled induction motor drive. IEEE Transactions on Industrial Electronics, Feb. 1997; 44:140-143.

[11] Qiao JG, Lu ZX. DFIG power controller modeling and simulation. Power System Automation, 2007; 31:34-37.

[12] Pena R, et al. Doubly fed induction generator using back-to-back PWM converters and its application to variable-speed windenergy generation. IEE Proceedings-Electric Power Applications, may 1996; 43:231-241.

[13] Xu Y, Chen Y, Mei SW. Transient simulation model of wind generator. Power System Automation, 2011; 35:8.

[14] Deng QY, Zhong LX, Dong L. Stator flux oriented vector control applied in induction motor flux observer model. Electric Technology Magazine, 2007; 22:30-34.

[15] Zhang CP, Lin F, Song WC, et al. Stator current vector oriented induction motor rotor flux estimator and its application. China Electrical Engineering, 2003; 23:155-158. 